\title{
Research on the Coordinated Development Strategy of Logistics Industry and Regional Economy in Beijing, Tianjin and Hebei Province against the Background of Big Data
}

\author{
Li Zhang ${ }^{\mathrm{a}}$, Jiaxin $\mathrm{Li}^{\mathrm{b}}$, Xiangxiang Wang ${ }^{\mathrm{c}}$ \\ Tianjin University of Science \& Technology, Tianjin ,300222, China. \\ ajannyzl@163.com, bjancy94@sina.com, c18322695586@163.com
}

Keywords: Logistics, Regional Economics, Beijing-Tianjin-Hebei, Big Data.

\begin{abstract}
The competitiveness of regional economy is a measure, which is an important indicator to measure the level of national economic development. Beijing-Tianjin-Hebei integration is the third pole of China's economic growth in the recent years, has received great attention. The era of big data expedites many professions, one of the support for economic development is logistics, which is a basic composite industry and plays an important role in the tertiary industry. In the designated area of collaborative development planning should be in depth deliberation. Therefore, in the era of big data, how to combine the characteristics and the advantages of the Beijing-Tianjin-Hebei region for the development of logistics planning, is not only the moment to promote regional economic development important content, but also a strong support of accelerate the integration process.
\end{abstract}

\section{Introduction}

Logistics, as a kind of composite industry that combines different fields and regions to achieve economic development through communication and interoperability, has important practical value in the current stage of China's industrial restructuring and adjustment. As another key regional planning and development project after the Yangtze River Delta and the Pearl River Delta Economic Zone, the Beijing-Tianjin-Hebei region should further develop logistics in the direction of the rising sun, combine its own advantages to create value, and stimulate the overall coordinated development of the regional economy.

\section{Research Status}

Today, the regional economy has played an active role in promoting the promotion of the overall economic level. As an important factor in promoting the development of economic clusters, the logistics industry occupies a major position in the development strategic planning of each country. Foreign experts and scholars began to realize the role of logistics in promoting the economy from an early stage, and analyzed its effect from a multidimensional perspective. Melendez (2001) believes that the construction of transportation infrastructure and the level of logistics development have a crucial role in promoting the economic development of a country or a region [1]. Markus Hesse (2004) found out from the case study of Berlin, Germany that the development of the regional economy will inevitably increase the service demand for the logistics industry, and thus put forward higher requirements for the distribution of logistics supply [2]. Yasanur Kayikci (2010) pointed out that an efficient logistics center can bring more profits for the development of social economy and enhance its own competitiveness [3].

Although the development of China's logistics industry started relatively late, there are now more and more experts concerned about the development of this field. For example, Zhang Meiqing, Zhou Ye, and Zhou Changlong (2012) analyzed the coordination relationship between logistics industry and regional economic development through symbiosis theory [4]. Zhang Yazhen (2014) analyzed the relationship between logistics and regional economy by analyzing their relationship [5]. Li Mingfang and Xue Jingmei (2015) analyzed the Beijing-Tianjin-Hebei region based on the structure of the shaft-spoke logistics network, and proposed development suggestions for the current status of 
different regions [6]. However, most scholars have not combined the analysis of big data and the status quo in the Beijing-Tianjin-Hebei region. Therefore, we must analyze the development of big data logistics from a global perspective and propose more realistic improvement measures.

\section{China's Big Data Logistics Development}

As early as September 2008, the world's most authoritative scientific journal, "Nature," used big data as a special issue to report that it will play an important role in different fields. In China, the word "big data" first appeared in the 2014 "Government Work Report". Since then, Big Data has become a basic strategic resource for the development of China's economic industry, and has promoted the development of many industries. Logistics is one of them.

Big data is the first to promote the transformation of the operating model, in order to obtain more data resources faster and more accurate, more and more companies have cooperated. For example, in 2013, Alibaba Group co-invested in more than ten courier companies and financial institutions and established “Rookie Network Technology Co., Ltd.”, which achieved connection with 228 countries' logistics networks, and built 617 transit centers and 176,000 nationwide. The planning and design of outlets has enabled the construction of a platform system for the real-time synchronization of logistics information in the e-commerce field. For another example, in June 2015, SF, Shentong, Yunda and other companies jointly invested in the establishment of Fengchao Technology Co., Ltd. to jointly develop and implement the Fengchao Express Co., and obtained more commercial users and achieved the last logistics.

In addition, the combination of big data thinking mode and traditional business philosophy makes the company make adjustments in decision-making and personnel management. E-commerce companies collect and collect big data to conduct more comprehensive analysis and forecast of future product sales, formulate more reasonable, higher-quality and more targeted sales solutions, improve the company's decision-making accuracy, and thus the competitiveness of enterprises. Make improvements. Logistics companies can track and analyze the status of their transportation vehicles and their work performance through the collection of big data. They can formulate timely and efficient maintenance plans and employee training programs to not only avoid possible accident safety. Hidden risks can also fully mobilize the enthusiasm of employees in the company and bring greater benefits to the company.

\section{The Interaction Between Regional Economy and Logistics}

The interaction between regional economy and logistics has formed a complex coupled coordination relationship[5]. That is, the development level of regional economy directly affects the foundation of logistics development, and logistics accelerates the formation of the scale of industrial agglomeration between regions. Promote the development of the regional economy.

\subsection{The Promotion of Regional Economy on Logistics Development}

The industrial development structure of the regional economy determines the level of core competitiveness, and its vigorous development will inevitably bring about more interactions between business flows and information flows, greatly increasing the demand for logistics. It can be said that the faster the regional economy develops, the greater the demand for logistics in the region. In addition to the direct stimulation of the development of the industry brought about by the increase in demand, this promotion is also reflected in the following aspects.

Regional economy promotes the formation of the logistics industry structure

The initial development of logistics is parasitic to the flow of commodities brought about by economic development. Therefore, the type, structure, and scale of economic development in the region all play an important role in the type and scope of logistics service development in the region. For example, in the central and western regions of China, where development is mainly agriculture, it is necessary to improve the overall capacity of transporting large cargoes by optimizing the routes and constantly updating and perfecting transportation methods and transportation equipment. The logistics mainly satisfies the required service types in the region, so the industrial development 
structure of the regional economy has a certain influence on the formation of the logistics industry structure.

(2) Regional economy promotes the expansion of the scale of logistics industry

Logistics is a highly circulated industry that depends on the active market environment and a good market foundation brought about by the economic development in the region. With the continuous development of the regional economy, business activities will become more and more frequent, so that the space in which logistics can be used will continue to expand, and the range of customers that can establish stable and cooperative relationships will also expand.

(3) The regional economy promotes the improvement of the level of the logistics industry

Relatively speaking, the higher the level of regional economic development, the stricter the standards for logistics requirements. For example, in the eastern part of China, the development of manufacturing and high-tech industries is the mainstay. The products produced by these industries require a higher level of service for logistics. The average enterprise cannot allocate too much energy and financial resources to improve the corresponding conditions. This has prompted a number of third-party logistics companies to begin to rise and upgrade the overall level of the logistics industry. In addition, with the improvement of the overall level of the regional economy, it will attract more investment and talent pool, advanced management concepts and technologies will also promote the further improvement of the level of the logistics industry.

\subsection{Promotion of Logistics Development to Regional Economy}

(1) Logistics promotes the optimization of regional economic structure

Nowadays, with the continuous improvement of the overall operation of the economy, the focus of the labor force has gradually shifted to the tertiary industry. At present, the degree of development of the tertiary industry structure in our country has not reached the height it deserves. Therefore, by fostering the clustered development of logistics, the overall advantages of the logistics can be brought into play to promote the economy, and the cooperation and development of trade and industry activities, information industry, finance and other industries in the region can be promoted, thereby improving the rationalization level of the regional economic structure.

(2) Logistics promote the efficiency of regional economic activities

Modern logistics is a complex industry with high value-added and intensive technologies. It can reduce the operational costs of input through continuous optimization and reorganization of various elements and nodes in the logistics network, and effectively integrate and efficiently use resources in the region. . The characteristics of scale and specialization in logistics can exert industrial relevance, promote cooperation between different companies, strengthen mutual cooperation and learn from each other, improve the overall core competitiveness of the region, and accelerate the operation efficiency of regional economies. Coordinate development goals.

(3) Logistics promotes the external relations of the regional economy

Foreign trade is the most powerful booster for promoting economic development. It can directly promote the accumulation of capital and expand the scale of economic efficiency. Logistics can break the boundaries of the region and strengthen the links within and outside the region, making the regional economy in different fields. All can achieve a balanced development, and then play a role in the radiation of the regional economy, continue to expand new economic agglomeration areas, and drive more areas to achieve economic growth.

\section{General Situation of Development of Beijing-Tianjin-Hebei Region at the Current Stage}

Regional economic development plays a crucial role in the promotion of the country's overall economic level. Therefore, following remarkable achievements in the development of the Yangtze River Delta and Pearl River Delta economic zones, the country has again adopted the Beijing-TianjinHebei integration development as a new development planning target. On April 30, 2015, the CPC Central Committee formally reviewed and approved the "Compendium of Beijing-Tianjin-Hebei Coordinated Development Plan," and put forward the goal of building Beijing-Tianjin-Hebei region as a new engine for promoting regional economic development. Specifically, it proposed the realization of industrial integration and logistics integration. A series of implementation rules. So far, 
the coordinated development of the Beijing-Tianjin-Hebei integration has achieved some successes. For example, in 2015, the national total GDP was 67.67 trillion yuan, and the total GDP of the BeijingTianjin-Hebei region was 6.9 trillion yuan, accounting for $10.2 \%$ of the total. Compared with the Yangtze River Delta with a total GDP of 11.31 trillion yuan, the gap is gradually narrowing. Although the overall economic development level of the Beijing-Tianjin-Hebei region is very strong, as shown in Figure 1, during the five-year period from 2010 to 2015, the GDP growth of the three regions of Beijing, Tianjin and Hebei is significant, but the difference between them is still large.

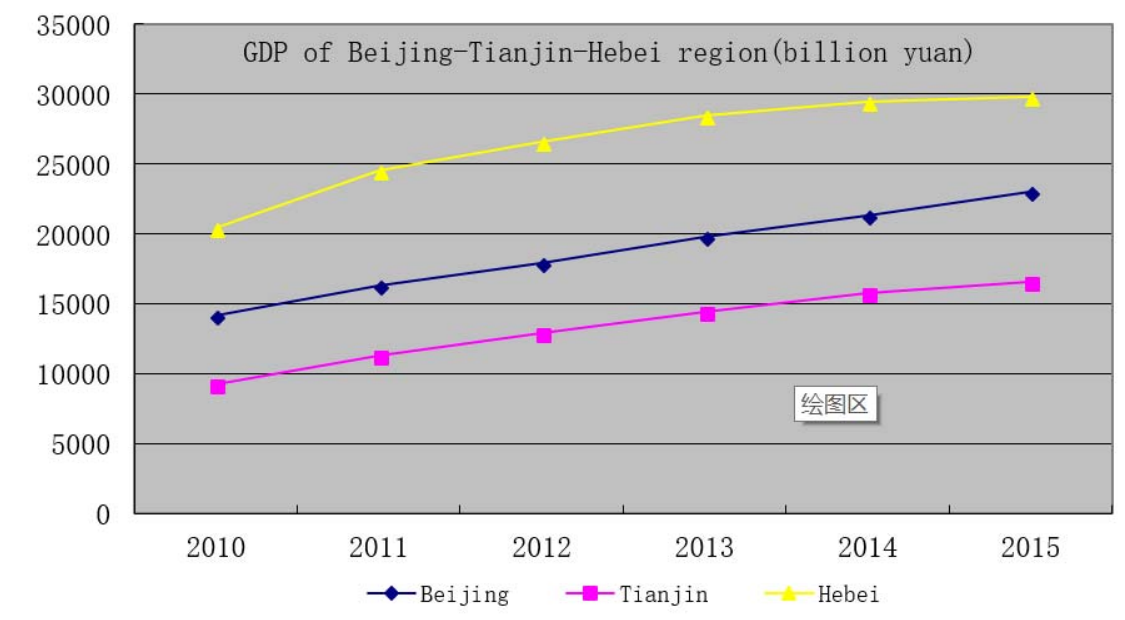

Figure 1. Distribution of GDP Changes in Beijing-Tianjin-Hebei Region, 2010-2015

(Source: China Statistical Yearbook 2015)

In the process of improving total GDP and promoting the coordinated development of regional economies, logistics, as the supporting force of the tertiary industry, has demonstrated an increasingly important boosting role in the process of increasing GDP. From Table 1, it can be seen that the proportion of the tertiary industry in the current stage of the Beijing-Tianjin-Hebei region accounts for a large gap between the proportion of the economic and industrial structure, and the level of development of the logistics industry as a supporting part of the tertiary industry in the three regions is even greater. It is a big difference. However, besides the proportion of the industrial structure of regional development, the obstacles encountered in the process of Beijing-Tianjin-Hebei integration have come from other sources.

Table 1. The proportion of the tertiary industry in Beijing, Tianjin, and Hebei in 2015

\begin{tabular}{|c|c|c|c|}
\hline & GDP of 2015(billion yuan) & $\begin{array}{l}\text { Year-on-year } \\
\text { growth }\end{array}$ & $\begin{array}{l}\text { The proportion of the tertiary } \\
\text { industry }\end{array}$ \\
\hline Beijing & 22968.60 & $6.9 \%$ & $79.8 \%$ \\
\hline Tianjin & 16538.19 & $9.3 \%$ & $52 \%$ \\
\hline $\begin{array}{c}\text { Hebei } \\
\text { Province }\end{array}$ & 29806.10 & $6.8 \%$ & $40.2 \%$ \\
\hline
\end{tabular}

First of all, there is a large difference in regional financial and economic levels. The difference between the financial correlation rate and the monetization rate, which shows a ladder-like distribution, shows this point. This imbalance in the distribution of regional funds will lead to difficulties in coordinating regional interests and low sharing levels. Although this is affected to a certain extent by administrative divisions, it is better to ensure the balance of regional income. Accumulated funds, to consolidate the foundation for meeting the various needs of follow-up industry development.

Secondly, it is affected by the geographical environment and the level of traffic development is uneven. As the capital, Beijing is the political, economic, and cultural center of the country. Whether it is the distribution of roads and railways or the construction of airport aerospace, Beijing has a fairly complete foundation and an absolute advantage. Because of the unique geographical location, Tianjin has a more prominent development of the port. The future economic orientation is also planned for the construction of a logistics center in the north. The supporting transportation systems such as highways, railways, and airports are also well-established and have relatively suitable development. 
The solid foundation. Transportation facilities in Hebei Province are far behind the level of Beijing and Tianjin. The uneven distribution is also one of the outstanding issues. Cities like Tangshan and Shijiazhuang have a convenient transportation network of a certain scale, but the radiation range is very small. Benefit to other cities.

Finally, it is the imperfect information exchange system and the lack of a timely and efficient information flow platform, resulting in a low level of overall informationization among regions. This has, to a large extent, constrained the development of the logistics industry. Due to the lack of information, interconnection, and timely delivery, it may cause internal competition, idle resources or waste caused by repeated operations. Moreover, poor communication of information will affect the overall and accuracy of government decisions, and it is not conducive to the regional economy. Long-term development.

\section{Prospects for Development of Big Data Logistics in Beijing, Tianjin, Hebei Province}

The integrated development of big data and logistics is an inevitable choice to promote better and faster economic development. The modern logistics service system proposed in the "Mid-term and Long-term Planning of Logistics Industry Development (2014-2020)" adopted by the State Council in June 2014. The construction and improvement of the project is inseparable from the support of big data. In view of the development of the Beijing-Tianjin-Hebei stage and the problems faced, we can analyze and improve from the following perspectives.

(1) Use policy controls to promote the overall development of the regional economy

Through the analysis of the comparative advantage theory[6], efficient and reasonable arrangements are made for the industrial division of labor and resources in the Jing-Jin-Ji region, and interest-adjustment institutions are established to maintain the balance between the regional income and losses. Considering the reality of urban development, Beijing should devote itself to further building into a national financial center and play a regulatory and decision-making role in the regional coordinated development system. Tianjin should make full use of the reform's first pilot opportunities and vigorously expand the reform experiment. More ways to create revenue; Hebei Province should actively realize its own industrial upgrading and transformation, around the Beijing and Tianjin to carry out related configuration, speed up the transfer of industries and expand the scale of capital accumulation. Only by making up for the obvious "shortcomings" in the economy, can we better make inter-regional construction work in order and gain long-term value.

(2) Overall planning of regional logistics facilities to improve the efficiency of logistics operations

At present, one of the problems with the logistics concentration in the Beijing-Tianjin-Hebei region is the unreasonable arrangement of the facilities, the repeated construction of some infrastructures or the low utilization rate, which does not exert the greatest value. For example, ports such as Tianjin Port and Tangshan Port are operating independently, which makes competition between them greater than their cooperation, resulting in repeated waste of resources. Another example is the airport shipping, Beijing Capital Airport has been in a state of overcapacity, while the adjacent Tianjin Binhai International Airport and Shijiazhuang Airport's resources have not been fully utilized, resulting in idle and waste of resources.

Therefore, it is necessary to speed up the planning of logistics facilities among cities, build a threedimensional logistics network combined with multiple transportation modes, and try to achieve seamless connection and improve logistics efficiency. Concretely speaking, Beijing can take the lead in adjusting the transportation layout, rationally diverting the tasks of cargo transportation to Tianjin, relieving the traffic pressure caused by overload operation and reducing part of the transportation costs; Tianjin should optimize its own road, rail and shipping lines. ,Strengthen communication with other transportation links and formulate concrete and feasible coordinated development plans; Hebei Province should increase the investment intensity and scope of traffic infrastructure construction, strengthen links with Beijing and Tianjin and other surrounding cities, and further improve logistics Supporting industry construction and improvement. Such a rational arrangement can better exert the influence of the Beijing-Tianjin-Hebei radioactive structure, narrow the economic gap, and achieve balanced regional development. 
(3) Optimize the type of logistics industry based on urban positioning and industrial structure

As a city that is positioned as a tertiary industry and an innovative industry, Beijing can strengthen the construction of a logistics base for consumer goods and strive to develop a logistics model that is complementary to and focuses on serving the tertiary industry. Tianjin should make full use of Lingang's advantages to develop port logistics parks, meet the development needs of high-tech industries and high-end equipment manufacturing industries, change the existing logistics parks with many unclear service targets, and scale and specialize. The direction of development. Hebei Province can use the advantage of land resources and numerous conditions for labor to realize the implementation of the manufacturing industry in Beijing and Tianjin and continue to develop the existing agricultural advantages, focusing on building large-scale logistics bases based on agriculture and industry, and developing agricultural products and Fresh foods, cold chain logistics development model.

(4) Efforts to cultivate the necessary talents and foster leading enterprises

The development of big data logistics requires more complex talents with professional knowledge. The Beijing-Tianjin-Hebei region can exert the advantages of attracting talent resources in Beijing and improve the cultivation of innovative talents based on the triple helix structure established by the government-business-school tripartite structure. Policy incentives and the issuance of social benefits are promoted to promote the flow of talent and encourage more talents to engage in this highly promising industry. Of course, not only talents need to be cultivated, but also leading enterprises that can play a leading role must be cultivated. Through policy assistance, they can independently develop relevant logistics information platforms, enhance their core competitiveness, and thus promote the positive development of the entire industry.

\section{Conclusion}

Under the background of the booming of big data, regional logistics, as one of the important functional elements in the regional economic system, has an important role in service and support. Through the analysis of the development status of the Beijing-Tianjin-Hebei region and the logistics network, a reasonable planning proposal is proposed, which not only can improve the level of regional logistics development, but also can further enhance the regional logistics competitiveness and ensure that the regional economy can achieve sustained and balanced development.

\section{References}

[1]. Melendez O, Maria Fernanda. The Logistics and Transportation Problems of Latin American Integration Efforts: The Andean Pact, A Case of Study[J]. Journal of Business Logistic, 2001(5):24-26.

[2]. Hesse M, Rodrigue J P. the transport geography of logistics and freight distribution[J]. Journal of transport,2004,12(3):171-184.

[3]. Y Kayikci. A conceptual model for intermodal freight logistics center location decisions[M]. Social and Behavioral Sciences,2010,2(3):6297-6311.

[4]. Zhang Meiqing, Zhou Ye, Zhou Changlong. Research on the Coordinated Development of Logistics Industry and Regional Economy Based on Symbiosis Theory[J]. Journal of Beijing Jiaotong University, 2012,11(1):27-34.

[5]. Zhang Yazhen. "Evaluation of Coupling Coordination Degree between Logistics Industry and Regional Economy"[J].Logistics Technology,2014,33(3):324-326.

[6]. Li Mingfang, Xue Jingmei. “Architecture and Strategy of the Axial-Spoke Area Logistics Network in Beijing, Tianjin and Hebei Provinces”[J]. Chinese Circulation Economy, 2015, 1:106-111. 